\title{
Assessment of clinico-radiological and biochemical markers of rickets: A hospital based prospective follow up study
}

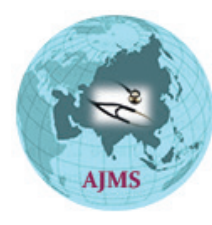

\author{
Sanjay Kumar ${ }^{1}$, Abha Jyoti ${ }^{2}$, Tushar Chaurasiya ${ }^{3}$, Rajesh Kumar', Nadeem Ashraf Khan ${ }^{5}$ \\ ${ }^{1}$ Professor, ${ }^{2,3}$ Assistant Professor, ${ }^{4}$ Junior Resident, Department of Biochemistry, ${ }^{5}$ Senior Resident, Department of \\ Orthopedics, GSVM Medical College Kanpur, Uttar Pradesh, India
}

Background: Rickets is a disorder of defective mineralization due to deficiency of calcium and vitamin $D$ and is more prevalent amongst the developing nations. Rickets has been ranked amongst the five most prevalent diseases in children of developing countries. The diagnosis of rickets is based on clinical features, biochemical studies and radiological signs and confirmed by response to treatment. Aims and Objectives: The purpose of this study is to evaluate the clinical, radiological and biochemical markers of the rickets by measuring the markers at the time of presentation, at 6 weekly intervals and after completion of treatment with standard regimen for rickets. Materials and Methods: 101 cases of nutritional rickets in age group 6 month to 18 years were allocated to receive combination therapy of calcium and vitamin-D according to their age and weight during a study period of 24 weeks. Radiographs (wrist and knee) and biochemical parameters (serum calcium, inorganic phosphate, alkaline phosphatase [ALP], and Vitamin-D), as well as clinical features, were evaluated at presentation, $6,12,18$, and 24 weeks and response of treatment and markers were assessed at subsequent interval. clinical, radiological, biochemical parameters were evaluated statistically with Chi-square test for qualitative and 2 or more different variables by ANOVAs respectively. A $\mathrm{P}<0.05$ was considered statistically significant analysis was done using Statistical Package for Social Sciences version 21.0. Results: At presentation, the mean dietary intake of calcium was low in all cases $(6.11 \pm 0.78 \mathrm{mg} / \mathrm{dl})$. Mean vitamin-D level was $(23.05 \pm 8.14 \mathrm{ng} / \mathrm{ml})$ indicative of vitamin-D deficiency. At the end of treatment (i.e., 24 weeks) clinical, radiological, and biochemical evidence of healing was observed. Normal serum ALP and complete radiological healing at 12 weeks was observed in $75 \%$ of subjects with the improvement of all markers. Conclusion: Children with rickets having low dietary calcium intake and low serum Vitamin-D levels have maximum number of markers at presentation. After intervention of combination regimen of calcium and Vitamin-D, remarkable improvement in clinical, radiological, and biochemical markers was found.

Key words: Biochemical markers; Clinico-radiological; Rickets
Access this article online

Website:

http://nepjol.info/index.php/AJMS DOI: 10.3126/ajms.v12i12.38766 E-ISSN: 2091-0576

P-ISSN: $2467-9100$

Copyright (c) 2021 Asian Journal of Medical Sciences

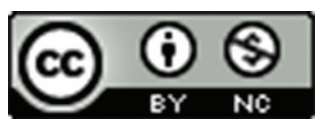

This work is licensed under a Creative Commons Attribution-NonCommercial 4.0 International License.

\section{INTRODUCTION}

Rickets is a disorder of growing children due to defective mineralization of newly formed bone matrix because of Vitamin D deficiency. ${ }^{1,2}$ Rickets has been ranked among the five most prevalent diseases in children of developing countries. ${ }^{3}$ The diagnosis of rickets is based on clinical features, biochemical studies, and radiological signs and confirmed by response to treatment. ${ }^{4}$ Exclusive breastfeeding without Vitamin D supplements for the baby, lack of sunlight exposure, inappropriate dietary intake, and poor housing would contribute to the development of rickets. ${ }^{5,6}$

The clinical signs and symptoms of rickets include bow legs, rachitic rosary, frontal bossing of the skull, widened wrist and ankle joints, and poor growth. Nutritional rickets is biochemically characterized by elevated serum 
alkaline phosphatase (ALP) activity, normal or decreased serum level of calcium and phosphate, secondary hyperparathyroidism, and decreased 25-OHD serum concentrations. ${ }^{7,8}$ Radiographic changes of active rickets are evident at growth plate of rapidly growing long bones. These changes reflect expansion of the cartilaginous growth plate and delayed mineralization. The junction of the mineralizing metaphysis with the cartilaginous physis (zone of provisional calcification) increase in longitudinal thickness. Consequently, the luscent gap between metaphysis and epiphysis expands because the shadow of the zone of provisional calcification is partially or totally invisible. ${ }^{9}$ The changes occurring in metaphysis may appear to be indistinct, frayed, and irregular on X-ray examinations. ${ }^{10}$ Though changes of rickets on radiographs are well characterized, there is no specific method for grading the severity of these changes that has been in general use. Consequently, it is difficult to compare objectively or follow radiographic improvement. To the best of our knowledge, only one study by Thacher et al., was conducted to evaluate the utility and reproducibility of a 10-point scoring method for measuring the severity of rickets. ${ }^{11}$

\section{Aims and objectives}

The purpose of this study is to evaluate the clinical, radiological, and biochemical markers of the rickets by measuring the markers at the time of presentation, at 6 weekly intervals, and after completion of treatment with a standard regimen for rickets.

\section{MATERIALS AND METHODS}

The study was conducted in the Department of Orthopaedics at our institution. The patients were followed up in the outpatient department on the basis of the provided visit. The clinical features, biochemical changes, and radiological findings were noted at every follow-up visit.

\section{Inclusion criteria}

The study included all children of nutritional rickets of age 6 months to 18 years, as well as patients presenting with recurrent LRTI, delayed milestones, diarrhea, or increase bone fractures.

\section{Exclusion criteria}

The patients of primary rickets associated with other comorbidities, major congenital malformations, chromosomal abnormalities, or any other metabolic disorders as well as patients of secondary rickets were excluded.

\section{Intervention}

Children of rickets were treated with calcium and vitamin D regime (Age 6-12 month with Vitamin D
(IU / DL) - Single dose of 50,000, Daily dose $\times 12$ weeks of 2000, Maintenance dose $\times 24$ weeks of 400 , with Calcium 300-400 mg/dl/day.

Age 1-12 years with Vitamin D (IU/DL) - Single dose of $1,50,000$, Daily dose $\times 12$ weeks of of $3,000-6,000$, Maintenance dose $\times 24$ weeks of 600 , with Calcium $600-1,200 \mathrm{mg} / \mathrm{dl} /$ day.

Age $>12$ years with Vitamin D(IU/DL) - Single dose of 3 Lacs, Daily dose $\times 12$ weeks of 6000 , Maintenance dose $\times 24$ weeks of 600 with Calcium $1300-1500 \mathrm{mg} / \mathrm{dl}$ day). In the follow-up visits, their serum biochemical markers and X-rays of wrist and knee were taken. Radiological markers were noted and the number of remaining clinical markers in the consecutive visits were noted.

\section{Outcome measures}

The following eight chief clinical parameters were used 1) Craniotabes 2) Harrison's sulcus 3) Rachitic changes 4) Widening of the wrist and knee 5) Bowing and Knock-knee 6) Pigeon chest 7) Joint swelling and tenderness 8) Difficulty in walking. Seven chief radiological parameters were 1) Epiphyseal enlargement 2) Splaying, fraying, and cupping 3) Rachitic rosary 4) Loss of provisional zone of calcification 5) Periosteal thickening 6) Pathological fracture 7) Coxa vara/valga. Biochemical markers were 1) serum calcium 2) serum phosphate 3) serum ALP 4) serum Vitamin-D. Each patient of rickets was followed up at 6 weekly interval and their clinical, radiological, and biochemical markers were assessed primarily at the time of presentation of the cases and then again at each follow up visit upto 24 weeks. The outcomes and overall improvement in all three markers were compared at the end of study period.

\section{Ethics}

Since the study involves human subjects, procedures followed were in accordance with the ethical standards of the responsible committee on human experimentation (institutional). Institutional Ethical Committee approval was taken for this study.

\section{Statistical analysis}

Improvement in clinical, radiological, and biochemical parameters were evaluated statistically with Chi-square and ANOVA tests. A $\mathrm{P}<0.05$ was considered statistically significant. The data were analyzed using Statistical Package for Social Sciences version 21.0. Biochemical markers and anteroposterior and lateral radiographs were taken at every visit for comparison of the radiological markers with clinical markers. 


\section{RESULTS}

The study consisted of a total 101 cases who were clinically diagnosed and further confirmation by radiograph and biochemical investigations was done. Among the study population, 57 were male and 48 were female. About $27.73 \%$ cases were in the age group of 6 months to 1 year, $33.66 \%$ were in the age group of $1-6$ years, $27.72 \%$ were $6-12$ years and $11.88 \%$ cases were present in the age group of 12-18 years. The mean age was 5 years. 68 cases were from rural area and 43 cases from urban area. Among these, 15 cases belonged to the upper class, 26 to the middle class and 60 cases belonged to lower socioeconomic status. Prevalence among males is more and mostly found in rural communities belonging to lower socioeconomic status.

A total of eight clinical markers relevant to the general population were taken in the study. Five cases had craniotabes with frontal bossing, 7 had Harrison's sulcus, rachitic changes in the ribs were seen in 29 patients, widening of wrist and knee in 18 patients, bowing of lower limb in 34 patients, knock knee in 31 patients, pigeon chest deformity in 4 , three patients had difficulty in walking while joint swelling and tenderness was seen in 27 patients. Apart from these, some patients presented with more than one clinical marker with non-osseous features such as potbelly. Malnutrition with poor development, growth retardation, dental defect, and muscle weakness were also present (Table 1).

Earliest sign of clinical relief is pain and bony tenderness while delayed response is in the deformity of the lower limb. Signs of clinical relief were found after 6 weeks of treatment. Other associated symptoms returned to the normal range within 4 to 6 weeks. Some patients $(6.68 \%)$ did not respond, for whom Vitamin D therapy with 3 lac or 6 lac IU was given monthly, intramuscularly and symptoms were relieved. The patients with lower limb deformity such as genu valgum and genu varum which did not correct spontaneously were advised to undergo corrective osteotomy.

There was a total of seven parameters for assessment of radiological markers, and they were epiphyseal enlargement (34 cases), features of splaying fraying and cupping (78 cases), rachitic rosary (22 cases), loss of provisional zone of calcification (57 cases), periosteal thickening (41 cases), pathological fractures (2 cases) and coxa vara (1)/coxa valga (2). Apart from these, most of these patients had widening of epiphysis and metaphysis (Figures 1 and 2). After a period of 24 weeks, $85.5 \%$ cases showed radiological healing while the rest did not respond with the regime. Vitamin-D levels

\begin{tabular}{|c|c|c|c|c|c|c|c|}
\hline \multirow{2}{*}{$\begin{array}{l}\mathrm{N}=101 \\
\text { Clinical markers }(n=8)\end{array}$} & \multicolumn{7}{|c|}{ Number of cases present } \\
\hline & At presentation & 6 weeks & 12 weeks & 18 weeks & 24 weeks & Total & Chi-square test \\
\hline 8 & 10 & 4 & 2 & 1 & 0 & 17 & $\chi^{2}=245$ \\
\hline 7 & 8 & 3 & 1 & 0 & 0 & 12 & Diff=32 \\
\hline 6 & 7 & 3 & 2 & 1 & 0 & 13 & $P<0.001$ \\
\hline 5 & 13 & 6 & 3 & 2 & 0 & 24 & (Highly significant) \\
\hline 3 & 20 & 28 & 30 & 20 & 7 & 105 & \\
\hline 2 & 24 & 20 & 22 & 16 & 18 & 100 & \\
\hline 1 & 2 & 11 & 24 & 36 & 32 & 106 & \\
\hline 0 & 1 & 1 & 3 & 7 & 39 & 51 & \\
\hline
\end{tabular}

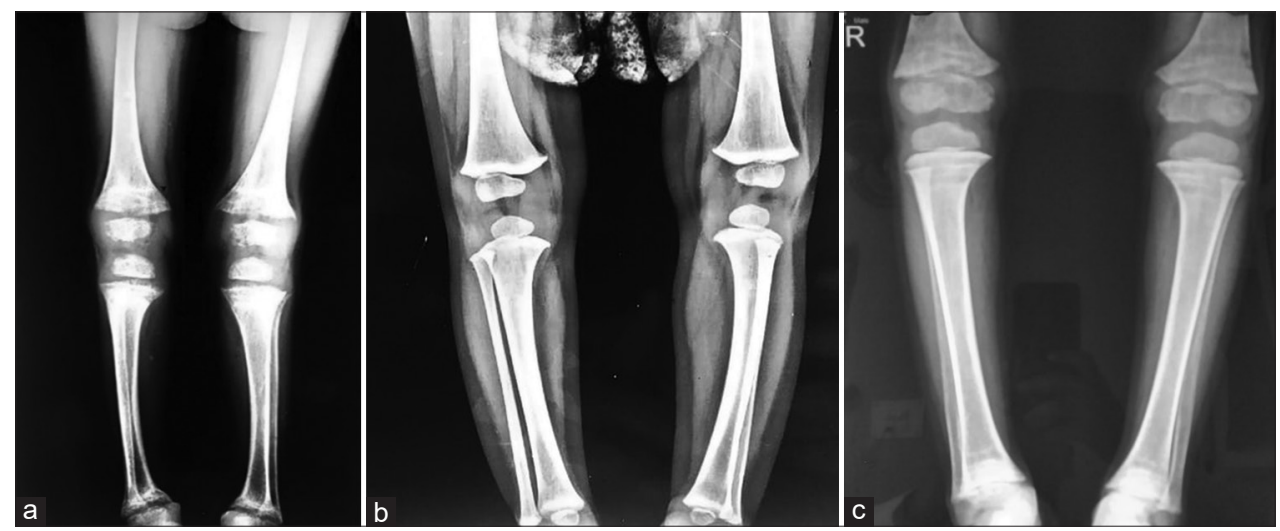

Figure 1: (a) At presentation, (b) at 6 weeks, (c) at 12 weeks 
are directly correlated with the severity of rickets. At presentation, 22 cases had $<30 \mathrm{nmol} / 1$ Vitamin-D and more radiological markers. At the end of 6 weeks, when all biochemical parameters started increasing towards the normal level, radiological markers started healing. Serum ALP most closely related to the severity to the radiological rickets (Table 2 ).

There were 4 biochemical parameters which were taken into account in our study. These were serum calcium, serum phosphate, serum ALP, and serum vitamin- $\mathrm{D}_{3}$. Other markers such as serum PTH and serum cholesterol were not taken as they were costlier investigations and were not feasible for most patients. Serum calcium levels were at significantly lower levels at the time of presentation (mean value $6.08 \mathrm{mg} / \mathrm{dl}$ ) and serum phosphate level (mean value $3.99 \mathrm{mg} / \mathrm{dl}$ ) was also low. Both values started rising on treatment with standard regimen of rickets. After 6 weeks on $1^{\text {st }}$ follow-up, serum calcium and serum phosphate values came near-normal range, and after 18 weeks, their mean values became normal i.e. $8.05 \mathrm{mg} / \mathrm{dl}$ and $5.08 \mathrm{mg} / \mathrm{dl}$. Serum ALP levels at the time of presentation (mean value $651 \mathrm{IU} / \mathrm{L}$ ) were significantly higher than the normal value (44-115 IU/L). Serum ALP closely related with severity of the rickets. During the course of the study, serum ALP levels followed a gradual pattern of fall, with a mean starting value during the first $\mathrm{OPD}$ visit of $651 \mathrm{IU} / \mathrm{L}, 582 \mathrm{IU} / \mathrm{L}$ at 6 weeks, $447 \mathrm{IU} / \mathrm{L}$ at 12 weeks, $361.61 \mathrm{IU} / \mathrm{L}$ at 18 weeks, and coming to normal range (115.73) after 24 weeks of treatment (Table 3).

Clinical, radiological, and biochemical markers which were resolved at the end of follow up (24weeks) interpreted as follows - clinical $93.327 \%$, radiological $85.55 \%$, biochemical $98.44 \%$ while those Not resolved are as follows - clinical 6.68\%, radiological 14.1\%, biochemical 5.66\%. $\chi^{2}=2.97, \mathrm{P}<0.05$ (Significant).

\section{Radiological findings}

Improvement in the calcification around the knee in Figure 1 and around wrist after vitamin D administration.
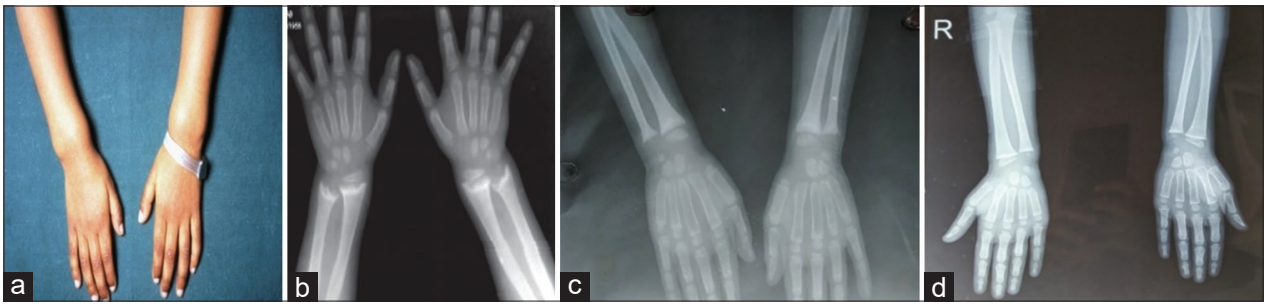

Figure 2: (a and b) At presentation, (c) at 6 weeks, (d) at 12 weeks

Table 2: Association between the number of radiological markers in study population with time interval

\begin{tabular}{|c|c|c|c|c|c|c|c|}
\hline \multirow{3}{*}{$\begin{array}{l}\mathrm{N}=101 \\
\text { Radiological markers }(\mathrm{n}=7)\end{array}$} & \multicolumn{5}{|c|}{ Number of cases present } & \multirow[t]{3}{*}{ Total } & \multirow[t]{3}{*}{ Chi-square test } \\
\hline & \multirow{2}{*}{$\begin{array}{c}\text { Pre-treatment } \\
\text { At presentation }\end{array}$} & \multicolumn{4}{|c|}{$\begin{array}{l}\text { Post-treatment } \\
\end{array}$} & & \\
\hline & & 6 weeks & 12 weeks & 18 weeks & 24 weeks & & \\
\hline 7 & 26 & 15 & 8 & 5 & 3 & 57 & $\chi^{2}=249.60$ \\
\hline 6 & 22 & 18 & 10 & 3 & 1 & 54 & Diff=28 \\
\hline 5 & 20 & 24 & 10 & 4 & 2 & 60 & $P<0.001$ \\
\hline 4 & 10 & 13 & 22 & 9 & 3 & 60 & (Highly significant) \\
\hline 3 & 10 & 14 & 28 & 14 & 9 & 75 & \\
\hline 2 & 5 & 5 & 15 & 29 & 22 & 76 & \\
\hline 1 & 7 & 6 & 3 & 23 & 35 & 74 & \\
\hline 0 & 1 & 3 & 5 & 14 & 26 & 49 & \\
\hline Total & 101 & 101 & 101 & 101 & 101 & & \\
\hline
\end{tabular}

Table 3: Mean values of biochemical markers with response of treatment

\begin{tabular}{|c|c|c|c|c|c|c|}
\hline \multirow{2}{*}{$\begin{array}{l}\text { Serum biochemical } \\
\text { markers }(n=101)\end{array}$} & \multirow{2}{*}{$\begin{array}{c}\text { Pre-treatment values } \\
\text { At presentation } \\
\text { (Mean } \pm S D)\end{array}$} & \multicolumn{4}{|c|}{ Mean value of serum markers during treatment } & \multirow[t]{2}{*}{$P$ value } \\
\hline & & $\begin{array}{c}6 \text { weeks } \\
\text { (Mean } \pm S D)\end{array}$ & $\begin{array}{c}12 \text { weeks } \\
\text { (Mean } \pm S D)\end{array}$ & $\begin{array}{c}18 \text { weeks } \\
\text { (Mean } \pm S D)\end{array}$ & $\begin{array}{l}24 \text { weeks } \\
\text { (Mean } \pm S D)\end{array}$ & \\
\hline Calcium (mg/dl) & $6.11 \pm 0.78$ & $7.05 \pm 0.68$ & $7.23 \pm 2.75$ & $8.05 \pm 0.93$ & $9.42 \pm 0.68$ & $<0.001$ \\
\hline Phosphate (mg/dl) & $3.99 \pm 0.58$ & $4.35 \pm 0.69$ & $4.51 \pm 0.54$ & $5.08 \pm 0.72$ & $5.33 \pm 0.71$ & $<0.001$ \\
\hline $\begin{array}{l}\text { Alkaline } \\
\text { phosphatase (iu/l) }\end{array}$ & $651 \pm 242.1$ & $582.96 \pm 203.41$ & $447.34 \pm 95.82$ & $361.6 \pm 107.42$ & $115.73 \pm 44.77$ & $<0.001$ \\
\hline Vitamin- $D_{3}(\mathrm{mmol} / \mathrm{l})$ & $23.05 \pm 8.14$ & $38.85 \pm 8.40$ & $76.83 \pm 16.23$ & $78.31 \pm 15.6$ & $94.63 \pm 9.70$ & $<0.001$ \\
\hline
\end{tabular}




\section{DISCUSSION}

Rickets remains a major public health problem in developing countries like India. The etiopathogenesis of rickets is thought to be multifactorial, for example, lack of exposure to sunlight, prolonged breastfeeding, multiple pregnancies, and lack of supplementation of food rich in Vitamin D. The relationship between Vitamin D and feeding pattern, duration of breastfeeding, age of complementary feeding, children and mother selective type of food, number of deliveries, sun exposure, clothing, and house type were also assessed. Nevertheless, the age at which to introduce complementary feeding, duration of complementary feeding, appropriate frequency of feeding, content, and factors affecting intake of complementary foods are beyond the scope of the current study and require further study.

In our study, genu-varum deformity was most common. Other features such as beading of the rib cage, Harrison's sulcus, bony tenderness at wrist and knee were other common features. Many studies showed that lack of sunlight increases the risk of rickets. ${ }^{12}$ In general, the distribution of rickets among children was decreased with increasing exposure frequency to sunlight. The more the child was exposed to sunlight, the more was the production of vitamin $\mathrm{D}$ in the skin. This result is consistent with other studies..$^{13}$ Mothers, who sought advice from both doctors and mother and child-care workers, were found to have the lowest number of rachitic children. ${ }^{14}$

In addition to the clinical features, the rachitic children also demonstrated biochemical alterations. There was significant decrease in the mean values of serum Vitamin D, serum calcium, and serum phosphate levels. In contrast, serum ALP levels were significantly increased in rachitic children. The serum concentration of $25-\mathrm{OH}$ Vitamin $\mathrm{D}_{3}$ is an accepted index of Vitamin D nutritional status and should be restricted to the assessment of Vitamin D status. ${ }^{15}$

The first sign of response to therapy is the appearance of healing line of rickets - a radio-opaque line in the epiphysis signifying mineralization of provisional zone of calcification has begun, Dimitri followed his patients 6 weekly to see the response of treatment. ${ }^{16}$ In our study, healing line appears after 6 weeks, $46.5 \%$ recovered within 12 weeks, and $88.14 \%$ by 6 months. In our study, the mean time taken to radiological resolution is 5 months. Radiography in each visit helps to evaluate the response of healing of rickets.

Radiologically, more severe rickets took more time to resolve. Calcium along with vitamin- $\mathrm{D}_{3}$ leads to quicker resolution of radiological findings. ${ }^{17}$ Patients who were not responding to usual regimen of rickets were given Stoss therapy and most of them had resolution within 6 months.

\section{Limitations of the study}

Our study was limited due to small sample size and difficulty in follow up of patients due to corona pandemic.

\section{CONCLUSION}

All the three parameters clinical, radiological, and biochemical are required to evaluate the outcome measures in rickets patients.

\section{What is known}

Distal ends of radius and ulna were used as the radiological indicator for diagnosis and follow-up in nutritional rickets, whereas the distal femur was a better radiological indicator. Thacher's 10-point scoring system is a very useful tool and the only system for assessing the severity and grading radiological changes of nutritional rickets and its follow-up that aids in monitoring improvement.

\section{What this study adds}

Non-osseous clinical markers and osseous radiological markers of rickets improved within a month in cases who presented at an early age. Serum ALP was closely related to the severity of the disease and serum vitamin-D level related to the prognosis and outcome of the disease. All the three parameters clinical, radiological, and biochemical are required to evaluate the outcome measures in rickets patients.

\section{ACKNOWLEDGMENT}

I would like to thank to all those patients who have cooperated by follow up during study and to staff (doctors, nurses, laboratory staff). There is no financial support from any where. Lastly I would like to thanks authorities of this hospital / medical college for their kind support to conduct the study.

\section{REFERENCES}

1. Holick MF. Mineral and vitamin D adequacy in infant fed human-milk or formula between 6 and 12 months of age. J Pediatr. 1994;117(2):S134-S142. https://doi.org/10.1016/s0022-3476(05)80011-3

2. Balch PA. Prescription for Nutritional Healing: The A-to-Z Guide to Supplements. $3^{\text {rd }}$ ed. New York: Avery; 2001. p. 45.

3. Thacher TD, Fischer PR, Pettifor JM, Lawson JO, Isichei CO, Reading JC, et al. A comparison of calcium, Vitamin D, or both for nutritional rickets in Nigerian children. $\mathrm{N}$ Eng $\mathrm{J}$ Med. 1999;341(8):563568.

https://doi.org/10.1056/nejm199908193410803 
4. Agarwal A and Gulati D. Early adolescent nutritional rickets. J Orthop Surg (Hong Kong). 2009;17(3):340-345 https://doi.org/10.1177/230949900901700320

5. Crocombe S, Mughal MZ and Berry JL. Symptomatic, Vitamin D deficiency among non-Caucasian adolescents living in the United Kingdom. Arch Dis Child. 2004;89(2):197-199. https://doi.org/10.1136/adc.2003.026799

6. Rajakumar M. Vitamin D, cod-liver oil, sunlight, and rickets: A historical perspective. Pediatrics. 2003;112(2):e132-e135. https://doi.org/10.1542/peds.112.2.e132

7. Kruse K. Pathophysiology of calcium metabolism in children with Vitamin D-deficiency rickets. J Pediatric. 1995;126(5):736-741. https://doi.org/10.1016/s0022-3476(95)70401-9

8. Ladhani S, Srinivasan L, Buchanan C and Allgrove J. Presentation of Vitamin D deficiency. Arch Dis Child. 2004;89(8):781-784.

9. Thacher TD, Fischer PR, Pettifor JM, Lawson JO, Manaster BJ and Reading JC. Radiographic scoring method for the assessment of the severity of nutritional rickets. J Trop Pediatr. 2000;46(3):132-139.

https://doi.org/10.1093/tropej/46.3.132

10. Woolf $A D$ and Pfleger B. Burden of major musculoskeletal conditions. Bull World Health Organ. 2003;81(9):646-656.

11. Thacher TD, Fischer PR, Pettifor JM, Lawson JO, Isichei CO and Chan GM. Case-control study of factors associated with nutritional rickets in Nigerian children. J Pediatr. 2000;137(3):367-373 https://doi.org/10.1067/mpd.2000.107527

12. Elzouki AY, Markestad T, Elgarrah M, Elhoni N and Aksnes L. Serum concentrations of Vitamin $D$ metabolites in rachitic Libyan children. J Pediatr Gastroenterol Nutr. 1989;9(4):507512.

https://doi.org/10.1097/00005176-198911000-00019

13. Specker BL, Ho ML, Oestreich A Yin TA, Shui QM, Chen XC, et al. Prospective study of Vitamin $\mathrm{D}$ supplementation and rickets in China. J Pediatr. 1992;120(5):733-739. https://doi.org/10.1016/s0022-3476(05)80236-7

14. Dratva J, Merten S and Ackermann-Liebrich U. Vitamin D supplementation in Swiss infants. Swiss Med Wkly. 2006;136(29- 30):473-481.

15. Grindulis $\mathrm{H}$, Scott PH, Belton NR and Wharton BA. Combined deficiency of iron and vitamin $D$ in Asian toddlers. Arch Dis Child. 1986;61(9):843-848. https://doi.org/10.1136/adc.61.9.843

16. Scheimberg I and Perry L. Does low Vitamin D have a role in pediatric morbidity and mortality? An observational study of Vitamin $D$ in a cohort of 52 postmortem examinations. Pediatr Dev Pathol. 2014;17(6):455-464. https://doi.org/10.2350/14-05-1491-oa.1

17. Dunn PM. Sir Robert Hutchison (1871-1960) of London and the causes and treatment of rickets. Arch Dis Child Fetal Neonatal Ed. 2005;90(6):F537-F539. https://doi.org/10.1136/adc.2004.065458

\section{Authors Contribution:}

SK- Concept and design of study, coordination and revision of the manuscript; AJ- Biochemically analysed, preparation of manuscript and revision of the manuscript; TC- Interpreted results and revision of the manuscript; RK- Reviewed literature, manuscript preparation, revision of manuscript, collected data and prepared first draft of manuscript; NAK- Statistically analysed and interpreted and revision of the manuscript.

Work attributed to:

GSVM Medical College and LLR Hospital, Kanpur - 208002, Uttar Pradesh, India.

\section{Orcid ID:}

Dr. Sanjay Kumar - (10 https://orcid.org/0000-0001-7330-0811

Dr. Abha Jyoti - (i) https://orcid.org/0000-0002-1950-4917

Tushar Chaurasiya - (1) https://orcid.org/0000-0002-4693-0372

Dr. Rajesh Kumar - (D) https://orcid.org/0000-0001-5816-1518

Nadeem Ashraf Khan - https://orcid.org/0000-0003-1009-6061

Source of Funding: None, Conflicts of Interest: None. 